\title{
Investigating social media activities: A study on celebrity posts
}

\author{
Naciye Güliz Uğur ${ }^{1}$, Merve Türkmen Barutçu ${ }^{2 *}$ \\ ${ }^{1}$ Department of Management Information Systems, Sakarya University, Adapazarı, Turkey \\ 2 Department of Business, Sakarya University, Adapazarı, Turkey
}

\author{
Keywords \\ Social media \\ Media richness theory \\ Celebrity endorsement \\ Received: 21 February 2018 \\ Accepted: 3 April 2018 \\ Published: 18 April 2018
}

\begin{abstract}
The research aims to establish methods to optimize social media engagement further and to increase revenues for businesses. The theoretical basis for this paper is the Media Richness Theory (MRT) by Daft and Lengel (1986), who originally made statements about the most suitable communication channel regarding its media richness for a given communication situation. The study conducted for this paper is quantitative. The data were gathered from a social media page with over 30,000 followers, and the analysis was conducted with a sample size of 315 Facebook posts. Our study continues a thread of research that investigates the application of the MRT to social media engagement. The study results did not only debunk commonly accepted social media myths about post time and day of the week, but they also confirmed previous studies are claiming celebrity endorsement, media richness, and its components to have significant effects.
\end{abstract}

\section{INTRODUCTION}

Social media engagement is one of the most crucial measures for the success of businesses and micro-businesses on social media (Coelho, Oliveira, \& Almeida, 2016; Hashem, 2016; Izhar, Baharuddin, Mohamad, \& Wan Hasnol, 2016). It is a more precise measure of audience interest in the services of a business than the number of followers because it varies with each post and allows for further analysis of the relating post type, messaging strategy, and its sub-elements. The MRT was based on traditional communication media such as newspapers, books, magazines, television, and radio (Daft \& Lengel, 1986; El Den, Adikhari, \& Adikhari, 2017). Over the last decade, the body of literature investigating social media phenomena grew proportionally with the broad diffusion and adoption of social media usage among the population (Aspasia \& Ourania, 2015; Tafesse, 2015). Thus, this paper continues a thread of research

which investigates the application of the MRT to social media engagement.
The high competition in social media is leaving marketers uncertain as to which kinds of messages yield the highest social media engagement. When broadcasting messages on social media, it is best to know which post types are best suited to effectively accommodate all information needed to express a message with a certain complexity. The question of how to optimize social media engagement with different message complexities and post types therefore becomes a pressing issue for marketers looking to grow their audiences successfully.

The research objectives are to analyze the association between social media engagement, media richness, message complexity, word count, post time, day of the week, and the resulting distribution of the social media engagement measures, e.g., clicks, likes, comments, and shares. Further, a re-

\footnotetext{
* corresponding author: Merve Türkmen Barutçu

†email: mturkmen@sakarya.edu.tr
} 
gression model shall be built to assign data-based weights to the engagement subcomponents clicks, likes, comments, and shares.

The purpose of the study is to explore how media richness, message complexity, the existence of a question in a post, word count, post time, and day of the week contribute to social media engagement. This paper shall test whether the assumptions of the MRT of Daft and Lengel (1986) are applicable to media richness expressed through different types of Facebook posts and their degrees of message complexity.

The analysis was conducted with a sample size of 315 Facebook posts. These posts originated from the Bill Gates personal Facebook page. One limitation of the study is the fact that naturally, certain post types, e.g., photos, enjoy a higher popularity. This could yield photos as the post type of choice, resulting in an unequal distribution of the different post types within the overall sample. Nevertheless, the sample size was still substantial enough to make statements about the general relationships between the examined variables. Furthermore, this distorted distribution towards photo posts has been observed in other scholarly studies (Aspasia \& Ourania, 2015; Basoglu, 2017).

Lim, Hwang, Kim, and Biocca (2015), who analyzed realtime backchannel communication on social media sites during the airing of various television programs, emphasized the importance of future research studying direct measures from social channels instead of a survey design similar to the one utilized in their study. This further supports the research design used in this study, which applies direct measurements of clicks, likes, comments, and shares. Contrary to Lim et al. (2015), this study does not rely on a survey method to gather indirect notions of social engagement. One social media engagement study, which emphasized commonplace limitations in contemporary data gathering processes, was the study of Men and Tsai (2013). They suggest that the use of a web-consumer panel and its limitations yield inherent threats to generalizability (Alahoul, Azizan, \& Alwi, 2016; Men \& Tsai, 2013). In this regard, the data gathering procedure of this paper offers additional advantages. Since this study used accumulated data from Facebook users who did not deliberately sign up to be a part of a web-consumer panel, consecutive distortive effects due to self-selection are assumed to be highly reduced.

Furthermore, studies aiming to explain how social media engagement can be enhanced are particularly important because relationships between social media engagement and gross-revenue have been identified in studies researching, e.g., movie sales (Oh, Roumani, Nwankpa, \& Hu, 2017; Rui, Liu, \& Whinston, 2013). For this reason, this paper is essential in establishing methods to further optimize social media engagement with the goal of increasing revenues for businesses.

\section{LITERATURE REVIEW}

There are many theories competing with the MRT, among them the most prominent one is, the Uses and Gratifications Theory (UGT) which has been vastly applied to investigate why people choose certain media (Hsu, Wang, Chih, \& Lin, 2015). Many scholars, particularly S. Y. Lee, Hansen, and Lee (2016), try to explain the motivations behind media selection, specifically with social media, e.g., Facebook. The UGT offers explanations for media use with focus on internal psychological motivators (S. Y. Lee et al., 2016; Iryani, 2017). This paints a strong contrast to the MRT (Daft \& Lengel, 1986), which mostly considers formal aspects of media choice. The MRT places an emphasis on information processing capabilities of media in each communication setting and its inherent communication requirements (Adroni \& Sitorus, 2017; Daft \& Lengel, 1986). To assess the fit of media, Daft and Lengel (1986) assert that the amount of communication, information flow, and feedback availability would inform the choice of media richness, which in turn influences communication effectiveness.

Daft and Lengel (1986) developed the MRT to find out why organizations process information. The theory is established based on the concept of uncertainty avoidance and the avoidance of equivocalness (Daft \& Lengel, 1986). Daft and Lengel (1986) find that organizations mainly process information to avoid task equivocality.

On one hand, Daft and Lengel (1986) claim that technology, interdepartmental relationships, and the environment directly impact information processing requirements due to different degrees of uncertainty and equivocality.

The communication technology aspect will be the focus of this study. Regarding technology assessment needed to maximize communication effectiveness, Daft and Lengel (1986) maintain that depending on analyzability (unanalyzable to analyzable) and the variety of information (low to high variety), the amount of information and the degree of media richness shall accordingly be adjusted. This aspect, which is specifically mentioned in the section technology of Daft and Lengel (1986) paper, will be used to derive the variables word count and question score as dimensions of message complexity. 


\section{Studies Challenging the MRT}

To challenge the MRT thirteen years after it was originally published by Daft and Lengel (1986) and Suh (1999) conducted a study to investigate whether the MRT would hold true for task information processing. Suh (1999) set up a laboratory experiment, attempting to confirm the MRT for text, audio, video, and face-to-face communication. Two tasks were given: intellective and negotiation. Suh (1999) measured task performance and satisfaction but could not find supporting evidence for the MRT. The performed Analysis of Variance (ANOVA) did not yield any significant results that could confirm a direct influence of the chosen media richness on task performance or satisfaction (Adora, 2017; Purba \& Sitorus, 2017; Suh, 1999). Nevertheless, this study should be cautiously considered since the subjects were students who had limited experience with video conferencing systems and electronic mail at the time (Suh, 1999). This was a result of a lack of the diffusion of sophisticated mainstream communication technology in the year 1999 when the study was conducted.

Timmerman (2002) found in his study that mindfulness and mindlessness needed to be accounted for to reliably explain media use as an outcome predicted by the MRT. His empirical results, however, showed that there is a lack of evidence to prove the concept of media richness (Timmerman, 2002).

Another study, which also disconfirmed the MRT, was an investigation conducted by Dennis and Kinney (1998). Higher media richness did not enhance the performance measured in "decision time, decision quality, consensus change or communication satisfaction" (Dennis \& Kinney, 1998) on the higher equivocality tasks.

Otondo, Van Scotter, Allen, and Palvia (2008) conducted an experiment to test whether the MRT would hold true for US navy recruiting materials. Otondo et al. (2008) tested text, audio, and video and their influence on communication effectivity and satisfaction. They performed a factor analysis which yielded the factors symbolism, social presence, personal focus, and information overload (Otondo et al., 2008). Otondo et al. (2008) assessed the MRT by stating The study provides two conclusions. First, the notions of media and information richness oversimplify the complex relationships between media, message, and receiver-based communication outcomes. The second is that media richness theory is a poor predictor of the effects of media type on communication outcomes and media richness, due to its non-monotonic nature across media types, and the weak relationships between media type and media features.

It is important to note that the study of Dennis and Kin- ney (1998) along with most other studies (El-Shinnawy \& Markus, 1997; Kinney \& Watson, 1992; Valacich, Mennecke, Wachter, \& Wheeler, 1994) which disconfirmed or only partially supported the MRT, were all conducted in the 1990s. These older studies represent a strong contrast to most of the recently published studies which confirm the MRT (Aspasia \& Ourania, 2015; Coelho et al., 2016; Coursaris, Van Osch, Balogh, \& Quilliam, 2014; Cvijikj, Spiegler, \& Michahelles, 2011; Kim, Spiller, \& Hettche, 2015; Tafesse, 2015; Sabate, Berbegal-Mirabent, Cañabate, \& Lebherz, 2014).

Many studies were conducted to compare media richness across different media. Park, Chung, and Lee (2012) compared e-mails to cell-phone texting and to Facebook wall postings to see how media richness differs in different textbased media.

S. Lee, Sun, and Thiry (2011) performed an analysis of media richness in an online dating setting. Besides exploring other relevant theories such as the information processing theory to explain the engagement with certain online dating profiles, they used the MRT in combination with the sufficiency principle to build their theoretical framework (S. Lee et al., 2011).

Lan and Sie (2010) performed a comparative study in regard to timeliness, accuracy, and media richness in social media networks, email, and Rich Site Summary (RSS). RSS is used by people to receive news updates on regularly changing web content. The goal of the study was to find out how mobile learning could be enhanced by various levels of media richness (Lan \& Sie, 2010).

Sun and Cheng (2007) conducted a study to identify the optimal approach to promoting consistent learning using the MRT. In an experimental research design, Sun and Cheng (2007) created four e-Learning instructional guides to find out which media type has the best fit to maximize the learning score and the learning satisfaction score.

\section{Media Richness Theory in Social Media}

Human behavior of individuals is the underlying concept that also describes the causes and effects described in the MRT (Daft \& Lengel, 1986). Hence, the theory can be applied to other communication situations in which human behaviors occur because of general human psychology. More specifically, the MRT is highly applicable in communication fields which involve information processing of highly complex versus less complex messages. These situations eventually yield different levels of equivocality and uncertainty for which the media richness shall be accordingly adjusted (Daft \& Lengel, 1986). 
Anandarajan, Zaman, Dai, and Arinze (2010) used the MRT, the CEM and the technology acceptance model to investigate the interaction effects of subjects' instant messaging within Generation Y. Their research focus makes this study especially interesting since this study will examine Facebook, which is mainly driven by people who belong to Generation Y.

Aspasia and Ourania (2015) investigated the social media interactions of Greek food manufacturing firms with their audiences on Facebook, specifically focusing on media richness, intensity, and responsiveness. In a descriptive analysis, they investigated whether the Greek food manufacturers were following the trends of contemporary consumer demands (Aspasia \& Ourania, 2015).

Kang, Tang, and Fiore (2014) also reviewed restaurants and their Facebook pages online. They revealed that fan pages which offered social-psychological and hedonic benefits were significantly more visited than pages which did not offer these benefits (Kang et al., 2014).

Kim et al. (2015) conducted a similar study among the five product categories "convenience, shopping, specialty, industrial and service." On the content side, they decided to code for self-oriented, interaction-oriented, and taskoriented posts (Kim et al., 2015). Kim et al. (2015) examined the media types text, photo, and video.

Sabate et al. (2014) researched brand post popularity in relation to media richness using data from five Spanish travel agencies. Sabate et al. (2014) examined the post types image, link, and video. They created a model for likes and comments separately (Sabate et al., 2014). Thus, they conducted an ANOVA and found a model for likes that could explain $55 \%$ of the variance with a $p$-value of .001 .

Coelho et al. (2016) also measured social media engagement across different business pages on Facebook by examining likes and comments. The post typology analysis, however, was done differently than in the predominant studies (Coelho et al., 2016). Instead of using the default post type categories image, video, URL, and status, Coelho et al. (2016) defined the categories advertising, event, fan, information, and promotion.

Cvijikj et al. (2011) analyzed 1049 posts from 14 major Facebook brand pages across different industries. They investigated the effects of moderator posts on fan pages regarding post type, date, interaction duration, likes, and comments. Referring to Cvijikj et al. (2011), the post types status, photo, link, and video were examined.

McKay (2015) conducted a study specifically for engagement in the non-profit sector and approached the research from a content perspective. Rather than categorizing by post type, the posts were coded by purposes, e.g., donation appeal or selling a product. McKay (2015) main finding is that "nonprofit organizations should focus on content that calls people to action like messages asking users to participate in lobbying and advocacy activities".

Coursaris et al. (2014) conducted a study which examined media richness of Facebook posts in regard to their post typology. Coursaris et al. (2014) found that higher media richness generally sparked more engagement, which were measured in likes, comments, and shares. Their literature review revealed that there were only about seven studies when Coursaris et al. (2014) published their article that was somewhat related to social media and media richness. However, none of them were specifically performed for Facebook post types in regard to media richness and post typologies.

\section{METHODS}

In accordance with the prevailing literature, likes, comments, and shares were used to measure social media engagement (Mandal, 2015). According to Mandal (2015), these metrics are cardinal to the success of micro businesses, since they can be "linked to the higher capabilities of the key objectives, such as higher awareness, higher engagement, higher word of mouth which would consequently lead to higher purchase intent."

In addition to that, this study will even account for clicks, a metric that Aspasia and Ourania (2015) did not measure in their own study but attributed a high importance to in the discussion of their paper. Stating "Facebook defines engagement as: 'Engaged users is the number of people who have clicked anywhere on your post'", Aspasia and Ourania (2015) reemphasize the need to include clicks as a central metric for engagement. In their study, Aspasia and Ourania (2015) found that the operationalization of the measurement engagement as executed in Coursaris et al. (2014) was insufficient, as it left out clicks, one of the most basic and important metrics of engagement. Clicks may be the least cognitively challenging form of engagement but it is the most occurring engagement action (Aspasia \& Ourania, 2015).

Instead of combining the dependent variables clicks, likes, comments, and shares into one compound measure of social media engagement, this study will test the effects of the independent variables on these sub-elements of social media engagement separately. 


\section{Media Richness Value}

Since the study will be applied to Facebook, media richness will be operationalized as social media post type, which is consistent with existing literature evolving around media richness and social media (Aspasia \& Ourania, 2015; Coelho et al., 2016; Cvijikj et al., 2011; Kim et al., 2015; Sabate et al., 2014; Su, Reynolds, \& Sun, 2015; Tafesse, 2015). Timmerman (2002) conducted a study to further refine the MRT and utilized the following criteria, which were derived from the initial study of Daft and Lengel in 1986 to operationalize media richness "(a) Potential for immediate feedback, (b) Capacity for multiple cues (audio, visual, etc.), (c) Ability to convey natural language, and (d) Personal focus" (p. 112). Consequently, these aspects were assessed when the post types were coded for media richness.

The post types which were used for this study were status (text only: lowest media richness), photo (photo with or without text: second lowest media richness), link (status containing additional link, where the link will be previewed as an image in the Facebook news feed: third lowest media richness), and video (video uploaded on Facebook with or without text: highest media richness). To execute the analysis, the media richness value was classified into the following groups: Group 1 (status [media richness value = 1]), Group 2 (photo [media richness value $=2$ ]), Group 3 (link [media richness value $=3$ ]), and Group 4 (video [media richness value $=4]$ ).

\section{Message Complexity}

When examining message complexity and of what it is composed, Daft and Lengel (1986) mention variety of information and analyzability as crucial elements. In this study, word count and question score represent the concepts of the variety of information and analyzability.

\section{Word count}

The first element of message complexity is word count. This measure represents the variety of information that Daft and Lengel (1986) describe in their paper because a higher variety of information can be expressed in a post with 150 words compared to a post with three words. To test whether there was a significant difference in engagement for different groups of word counts, the variable were grouped into low word count ( 0 to 19 words), medium word count (20 to 111 words), and high word count (112 to 450 words).

\section{Question score}

Upon examining the raw data, another pattern became evident: Self-reflective posts that urged audience members to offer feedback, opinions, help, or support were usually posted as a question. This type of post tends to be more complex, convoluted, ambiguous, and harder to analyze than straightforward posts containing no questions. Hence, this differentiation for questions specifically addresses the analyzability that Daft and Lengel (1986) mentioned as a subcomponent of message complexity. Subsequently, the question score will be coded into two groups: Group 1 [question score $=1$; if the posts contain no question] and Group 2 [question score $=2$, if there is a question in the post].

\section{FINDINGS}

This study extracted the two major concepts media richness and message complexity from the original MRT (Daft \& Lengel, 1986), providing significant results, especially for the independent variable media richness value. Other variables such as day of the week and post time were intentionally added to challenge commonly accepted beliefs, e.g., the claim that Facebook posts on weekends or in the evening perform better than posts that were published at other times (Ellering, 2016).

Among social media professionals, there is a popular belief that posts that are published on weekends get more social media engagement than posts which are published on weekdays (Ellering, 2016). This belief is often explained with, e.g., the tendency of people to search for different things on the internet on weekends and having more time on the weekend. The results of this study may not be generalizable to every social media page in all industries, and scholars should replicate this study to test whether the findings hold true for different samples. Nevertheless, the common misconceptions regarding day of the week and post time were effectively invalidated by showing that the differences in engagement were not significant.

\section{Post Time}

The same conclusion was reached for post time as that reached for day of the week. Despite the common assumption that post time may affect Facebook engagement because people tend to behave differently at work than at home, the results clearly show that there is no such relationship. All examined engagement variables were unaffected by post time. When shares were examined, however, post time differences accounted for a $p$-value of .063, which is approaching significance. 


\section{Question Score}

The question score is one element (along with word count) which represents the variable message complexity proposed by Daft and Lengel (1986). The independent variable question score only had a significant effect on likes ( $p$-value $=.01$ ). Posts which did not entail a question performed significantly better than posts with a question (across all post types, with likes being the only significant difference). This finding is somewhat surprising, given that the general social media advice recommends creating engaging posts that activate the audience or incite its interest by posting questions, quizzes, surveys, or contests. Since the results of this study cannot be generalized, the claim of interactive posts performing better cannot be dismissed across all industries. For the influencer market in information technologies, however, the results showed that people tended to like a post more if it did not contain a question.

\section{Word Count}

Word count, as the second subvariable of message complexity, showed two out of four dependent variables yielding significant results. The different word count groups resulted in significantly different numbers of likes ( $p$-value $=.007$ ) and comments ( $p$-value $=.046$ ). It shows the variable word count grouped into the three categories which were tested (low, medium, and high) to highlight the tendencies of the data. Posts with low word count resulted in more likes than posts with higher word count. In contrast, the relationship between word count and comments was inversed. Posts with high word counts received more comments than posts with a low word count.

When the cognitive effort required to read a lengthy post is considered, these results appear intuitive. Posts which require low effort to read (low word count) get a low effort engagement reaction (likes). Following this logic, posts which required a high cognitive effort (high word count) received significantly more reactions requiring high cognitive effort (comments). This can partially be explained by the behavioral investment made through reading a longer post and the need to cognitively justify that investment later through commenting, which is behavior that can be explained with the cognitive dissonance theory (Friedman \& Friedman, 1979).

The results for clicks and shares were inconclusive, yielding no significant differences. For shares, this can potentially be explained by the fact that it is the least occurring engagement metric and therefore did not accumulate enough data to yield significant differences (averages varying from 1.2 shares to 1.9 per post). For clicks, the results show that there was no significant difference in the data set based on word count. Thus, the recommendation for social media marketers is to focus on word count if they want to affect their likes or comments. Special attention should, however, be paid to the counterposing effect of increased word count, increasing comments while decreasing the likes.

\section{MRT}

The media richness value was shown to have a significant influence on the number of clicks, likes, and shares. When looking at the significance levels, media richness was by far the most significant across all engagement categories. Thus, it can be concluded that media richness is a more universal predictor than the other variables examined in this study. It is applicable to almost all engagement categories, whereas the elements of message complexity should always be assessed in the regarding goal context, e.g., the goal to achieve more likes or comments. The findings are aligned with the most recent studies in media richness research. As assessed in the literature review, media richness proved to be specifically applicable to social media engagement.

\section{CONCLUSION}

The special approach in this study was to research and contrast two categories of engagement influencers: commonly assumed but less scientifically tested variables (day of the week and post time (Ellering, 2016), and theoretically derived variables, which were already more extensively tested (media richness, word count, and question score (Daft \& Lengel, 1986). Additionally, the lack of a compound formula for social media engagement was identified and resolved by performing a linear regression with real- world data.

The popularly assumed influencers, post time and day of the week, showed no significant results. In contrast, the variables derived from the media richness theory showed significant results. The likes were shown to be significantly different for posts that entailed questions. Moreover, there were significant differences in likes and comments for posts with different word counts. Lastly, clicks, likes, and shares were significantly different depending on the media richness value (status, photo, link, or video). Therefore, the testing of these two categories of variables contributed to the debunking of popular social media myths, as the previous studies regarding media richness were for the most part confirmed and assumptions regarding post time and day of the week were dismissed. The study confirmed the robustness of the MRT. The fact that this study yielded significant results for the tested variables derived from the MRT and no significant results for effects that are commonly as- 
sumed by social media practitioners (Ellering, 2016) further reemphasizes the necessity of scientific inquiry to test hypotheses. One very prominent non-scientific article claimed higher engagement on, e.g., weekends (Ellering, 2016). But these claims were not confirmed using the scientific method. In our study the insignificant results, related to post time and day of the week may be explained by celebrity effect. Celebrities are well-known individuals who receive significant media attention. Also they are seen as credible sources of information (Goldsmith, Lafferty, \& Newell, 2000). The credibility of a celebrity can be described as the amount of positive characteristics that create and increase the acceptance of the information (Erdogan, 1999). For marketing projects, selection of a celebrity is a critical, difficult, and risky decision. In order to reduce the risk, brands choose celebrities, who are perceived as credible (Friedman \& Friedman, 1979). Celebrities on Twitter who tweet about brands and products are often seen by their followers as a fellow social media user, whether they are official brand endorsers or not (Schaefer, 2012). We assume that people intend to like, share or comment on celebrities' messages more than their usual friends. Because we examined a celebrity's account, the results that are in contrast with the literature may be under effect of the celebrity. On the other hand, there are several studies in the literature investigating celebrity effect and how they impact the way users behave (Basil, 1996; Erdogan, 1999; Kahle \& Homer, 1985; Silvera \& Austad, 2004). Therefore, it is well-known that people may behave extraordinary by the effect of a celebrity. Post time and day of the week are suggested as significant indicators in many studies.

As a second contribution, the newly created social media engagement formula should be discussed. Such a formula based on performance data has never been published before. Rather, the only attempt of formulating a compound social media engagement formula was based on an arbitrary assignment of subjective weights based on cognitive involvement to perform such engagement actions (Coursaris et al., 2014).

In summary, the results of the study did not only debunk commonly accepted social media myths about post time and day of the week, but they also confirmed previous studies claiming media richness and its components to have significant effects.

Furthermore, they equipped social media practitioners with a social media formula which is backed up by real world data, effectively helping them to tailor posts by optimizing the composition of their target variables clicks, likes, comments, and shares so that post reach, brand awareness, and hence potential engagement are maximized.

\section{LIMITATIONS AND RECOMMENDATIONS}

Examination of a celebrity's account is a limitation of our study, and results that differ by the literature should be evaluated under this limitation.

Since this study tested these relationships and reported insignificant results for post time and day of the week, it should encourage other scholars to replicate this study and apply it to different industries to see whether the results hold true.

\section{REFERENCES}

Adora, A. L. (2017). Students' performance of BSIE and BSHE in drawing subjects in the University of Eastern Philippines. Journal of Advanced Research in Social Sciences and Humanities, 2(4), 168-175. doi:https://doi.org/10.26500/jarssh -02-2017-0302

Adroni, N., \& Sitorus, P. M. (2017). Evaluation of badix information system implementation success in Telkomsel region of sumbagsel using DeLone \& McLean model. International Journal of Business and Economic Affairs, 2(3), 211-219. doi:https://doi.org/10.24088/ijbea-2017-23006

Alahoul, M. H. M., Azizan, N., \& Alwi, N. H. (2016). Factors that affect the use of Malaysian e-learning websites by visually impaired users in the transfer of islamic knowledge. Journal of Advanced Research in Social Sciences and Humanities, 1.(1), 30-40. doi:https://doi.org/10.26500/jarssh-01-2016-0104

Anandarajan, M., Zaman, M., Dai, Q., \& Arinze, B. (2010). Generation y adoption of instant messaging: An examination of the impact of social usefulness and media richness on use richness. IEEE Transactions on Professional Communication, 53(2), 132-143. doi:https://doi.org/10.1109/tpc.2010.2046082

Aspasia, V., \& Ourania, N. (2015). Greek food manufacturing firms' social media efforts: Evidence from facebook. ProcediaSocial and Behavioral Sciences, 175, 308-313. doi:https://doi.org/10.1016/j.sbspro.2015.01.1205

Basil, M. D. (1996). Identification as a mediator of celebrity effects. Journal of Broadcasting \& Electronic Media, 40(4), 478-495. doi:https://doi.org/10.1080/08838159609364370 
Basoglu, B. (2017). You tube or writing tube: A technology-mediated learning tool for TESOL. International Journal of Humanities, Arts and Social Sciences, 3(3), 98-105. doi:https://doi.org/10.20469/ijhss.3.20001-3

Coelho, R. L. F., Oliveira, D. S., \& Almeida, M. I. S. (2016). Does social media matter for post typology? Impact of post content on facebook and instagram metrics. Online Information Review, 40(4), 458-471. doi:https://doi.org/10.1108/ oir-06-2015-0176

Coursaris, C. K., Van Osch, W., Balogh, B. A., \& Quilliam, E. T. (2014). Social media marketing: Investigating empirical links between purchase involvement, strategy, content, and media type. In Conference Proceedings of American Academy of Advertising, New York, NY.

Cvijikj, I. P., Spiegler, E. D., \& Michahelles, F. (2011). The effect of post type, category and posting day on user interaction level on facebook. In Conference Proceedings Privacy, Security, Risk and Trust, Boston, MA.

Daft, R. L., \& Lengel, R. H. (1986). Organizational information requirements, media richness and structural design. Management Science, 32(5), 554-571. doi:https://doi.org/10.1287/mnsc.32.5.554

Dennis, A. R., \& Kinney, S. T. (1998). Testing media richness theory in the new media: The effects of cues, feedback, and task equivocality. Information Systems Research, 9(3), 256-274. doi:https://doi.org/10.1287/isre.9.3.256

El Den, J., Adikhari, P., \& Adikhari, P. (2017). Social media in the service of social entrepreneurship: Identifying factors for better services. Journal of Advances in Humanities and Social Sciences, 3(2), 105-114. doi:https://doi.org/10.20474/ jahss-3.2.4

Ellering, N. (2016). What 16 studies say about the best times to post on social media. Retrieved from https : //goo . gl/ELQCM4 (accessed on 23 April 2017)

El-Shinnawy, M., \& Markus, M. L. (1997). The poverty of media richness theory: Explaining people's choice of electronic mail vs voice mail. International Journal of Human-Computer Studies, 46(4), 443-467. doi:https://doi.org/10.1006/ ijhc.1996.0099

Erdogan, B. Z. (1999). Celebrity endorsement: A literature review. Journal of Marketing Management, 15(4), $291-314$. doi:https://doi.org/10.1362/026725799784870379

Friedman, H. H., \& Friedman, L. (1979). Endorser effectiveness by product type. Journal of Advertising Research, 5(3), 22 -24. doi:https://doi.org/10.1080/00913367.1976.10672647

Goldsmith, R. E., Lafferty, B. A., \& Newell, S. J. (2000). The impact of corporate credibility and celebrity credibility on consumer reaction to advertisements and brands. Journal of Advertising, 29(3), 43-54. doi:https://doi.org/10.1080/ 00913367.2000 .10673616

Hashem, T. N. (2016). The impact of social media on customers' image for mobiles. Journal of Advances in Humanities and Social Sciences, 2(5), 269-277. doi:https://doi.org/10.20474/jahss-2.5.3

Hsu, L. C., Wang, K. Y., Chih, W. H., \& Lin, K. Y. (2015). Investigating the ripple effect in virtual communities: An example of facebook fan pages. Computers in Human Behavior, 51, 483-494. doi:https://doi.org/10.1016/j.chb.2015.04.069

Iryani, . M. S. Y., W. I. (2017). Empowering family with social-psychology problem through Family Care Unit (FCU). International Journal of Humanities, Arts and Social Sciences, 3(2), 53-63. doi:https://doi.org/10.20469/ijhss.3.20003-2

Izhar, T. A. A., Baharuddin, M. F., Mohamad, A. N., \& Wan Hasnol, W. M. H. (2016). Using ontology for goal-based query to evaluate social media data. Journal of Advances in Humanities and Social Sciences, 2(2), 108-118. doi:https://doi.org/ $10.20474 /$ jahss-2.2.5

Kahle, L. R., \& Homer, P. M. (1985). Physical attractiveness of the celebrity endorser: A social adaptation perspective. Journal of Consumer Research, 11(4), 954-961. doi:https://doi.org/10.1086/209029

Kang, J., Tang, L., \& Fiore, A. M. (2014). Enhancing consumer brand relationships on restaurant facebook fan pages: Maximizing consumer benefits and increasing active participation. International Journal of Hospitality Management, 36, 145-155. doi:https://doi.org/10.1016/j.ijhm.2013.08.015

Kim, D. H., Spiller, L., \& Hettche, M. (2015). Analyzing media types and content orientations in facebook for global brands. Journal of Research in Interactive Marketing, 9(1), 4-30. doi:https://doi.org/10.1108/jrim-05-2014-0023

Kinney, S. T., \& Watson, R. T. (1992). The effect of medium and task on dyadic communication. In Proceedings of the International Conference on Information Systems, Dallas, TX.

Lan, Y. F., \& Sie, Y. S. (2010). Using rss to support mobile learning based on media richness theory. Computers \& Education, 55(2), 723-732. doi:https://doi.org/10.1016/j.compedu.2010.03.005 
Lee, S., Sun, Y., \& Thiry, E. (2011). Do you believe in love at first sight: Effects of media richness via modalities on viewers' overall impressions of online dating profiles. In Proceedings of the 2011 iConference, Seattle, Washignton, WA: DC.

Lee, S. Y., Hansen, S. S., \& Lee, J. K. (2016). What makes us click "like" on facebook? Examining psychological, technological, and motivational factors on virtual endorsement. Computer Communications, 73, 332-341. doi:https://doi.org/10 .1016/j.comcom.2015.08.002

Lim, J. S., Hwang, Y. C., Kim, S., \& Biocca, F. A. (2015). How social media engagement leads to sports channel loyalty: Mediating roles of social presence and channel commitment. Computers in Human Behavior, 46, 158-167. doi:https://doi.org/ 10.1016/j.chb.2015.01.013

Mandal, D. (2015). Social media adoption by microbusinesses (Unpublished doctoral dissertation). University of Waikato, Hamilton, New Zealand.

McKay, L. (2015). How social is social? Nonprofit audience engagement by types of facebook posts (Unpublished master's thesis). Gonzaga University, Spokane, Washington, WA: DC.

Men, L. R., \& Tsai, W.-H. S. (2013). Toward an integrated model of public engagement on corporate social networking sites: Antecedents, the process, and relational outcomes. International Journal of Strategic Communication, 7(4), 257-273. doi:https://doi.org/10.1080/1553118x.2013.822373

Oh, C., Roumani, Y., Nwankpa, J. K., \& Hu, H.-F. (2017). Beyond likes and tweets: Consumer engagement behavior and movie box office in social media. Information and Management, 54(1), 25-37. doi:https://doi.org/10.1016/j.im.2016.03.004

Otondo, R. F., Van Scotter, J. R., Allen, D. G., \& Palvia, P. (2008). The complexity of richness: Media, message, and communication outcomes. Information \& Management, 45(1), 21-30. doi:https://doi.org/10.1016/j.im.2007.09.003

Park, N., Chung, J. E., \& Lee, S. (2012). Explaining the use of text-based communication media: An examination of three theories of media use. Cyberpsychology, Behavior, and Social Networking, 15(7), 357-363. doi:https://doi.org/10 .1089 /cyber.2012.0121

Purba, P. R. ., \& Sitorus, P. M. (2017). Influence analysis of dissatisfaction, situational condition, and switching costs on the switching behavior of Telkomsel postpaid card customers in Batam city. International Journal of Business and Economic Affairs, 2(3), 193-205. doi:https://doi.org/10.24088/ijbea-2017-23004

Rui, H., Liu, Y., \& Whinston, A. (2013). Whose and what chatter matters? The effect of tweets on movie sales. Decision Support Systems, 55(4), 863-870. doi:https://doi.org/10.1016/j.dss.2012.12.022

Sabate, F., Berbegal-Mirabent, J., Cañabate, A., \& Lebherz, P. R. (2014). Factors influencing popularity of branded content in facebook fan pages. European Management Journal, 32(6), 1001-1011. doi:https://doi.org/10.1016/j.emj.2014.05 .001

Schaefer, M. (2012). The tao of twitter: Changing your life and business 140 characters at a time. Columbus, OH: McGraw-Hill.

Silvera, D. H., \& Austad, B. (2004). Factors predicting the effectiveness of celebrity endorsement advertisements. European Journal of Marketing, 38(11/12), 1509-1526. doi:https://doi.org/10.1108/03090560410560218

Su, N., Reynolds, D., \& Sun, B. (2015). How to make your facebook posts attractive: A case study of a leading budget hotel brand fan page. International Journal of Contemporary Hospitality Management, 27(8), 1772-1790. doi:https://doi .org/10.1108/ijchm-06-2014-0302

Suh, K. S. (1999). Impact of communication medium on task performance and satisfaction: An examination of mediarichness theory. Information and Management, 35(5), 295-312. doi:https://doi.org/10.1016/s0378-7206(98)00097 $-4$

Sun, P. C., \& Cheng, H. K. (2007). The design of instructional multimedia in e-learning: A media richness theory-based approach. Computers \& Education, 49(3), 662-676. doi:https://doi.org/10.1016/j.compedu.2005.11.016

Tafesse, W. (2015). Content strategies and audience response on facebook brand pages. Marketing Intelligence \& Planning, 33(6), 927-943. doi:https://doi.org/10.1108/mip-07-2014-0135

Timmerman, C. E. (2002). The moderating effect of mindlessness/mindfulness upon media richness and social influence explanations of organizational media use. Communication Monographs, 69(2), 111-131. doi:https://doi.org/10.1080/ 714041708

Valacich, J. S., Mennecke, B. E., Wachter, R. M., \& Wheeler, B. C. (1994). Extensions to media richness theory: A test of the task-media fit hypothesis. In Proceedings of the 27th Hawaii International Conference on System Sciences, Hawaii, HI. doi:https://doi.org/10.1109/hicss.1994.323504 